\title{
THE PROBLEM OF KNOWLEDGE
}

PROVOKED BY THE COLLABORATIVE ACTION

\section{OF TECHNOLOGY AND HUMAN}

Hyunkyoung Cho

Post-Doctoral Researcher, ASPECT Program, Virginia Tech

hkcho@vt.edu

\section{Introduction}

"Truth as Circe. Error has turned animals into men; might truth be capable of turning man into an animal again?"52

The truth is Circe's potion-it turns human into swine. The magical and fatal transformation reminds us of knowledge/power relations. The paradox is that no one drinks the potion nowadays, since there are too many antidotes and anesthetics.

${ }^{52}$ Friedrich W. Nietzsche, Human, All Too Human (Cambridge: Cambridge University Press, 1996), 182 . 


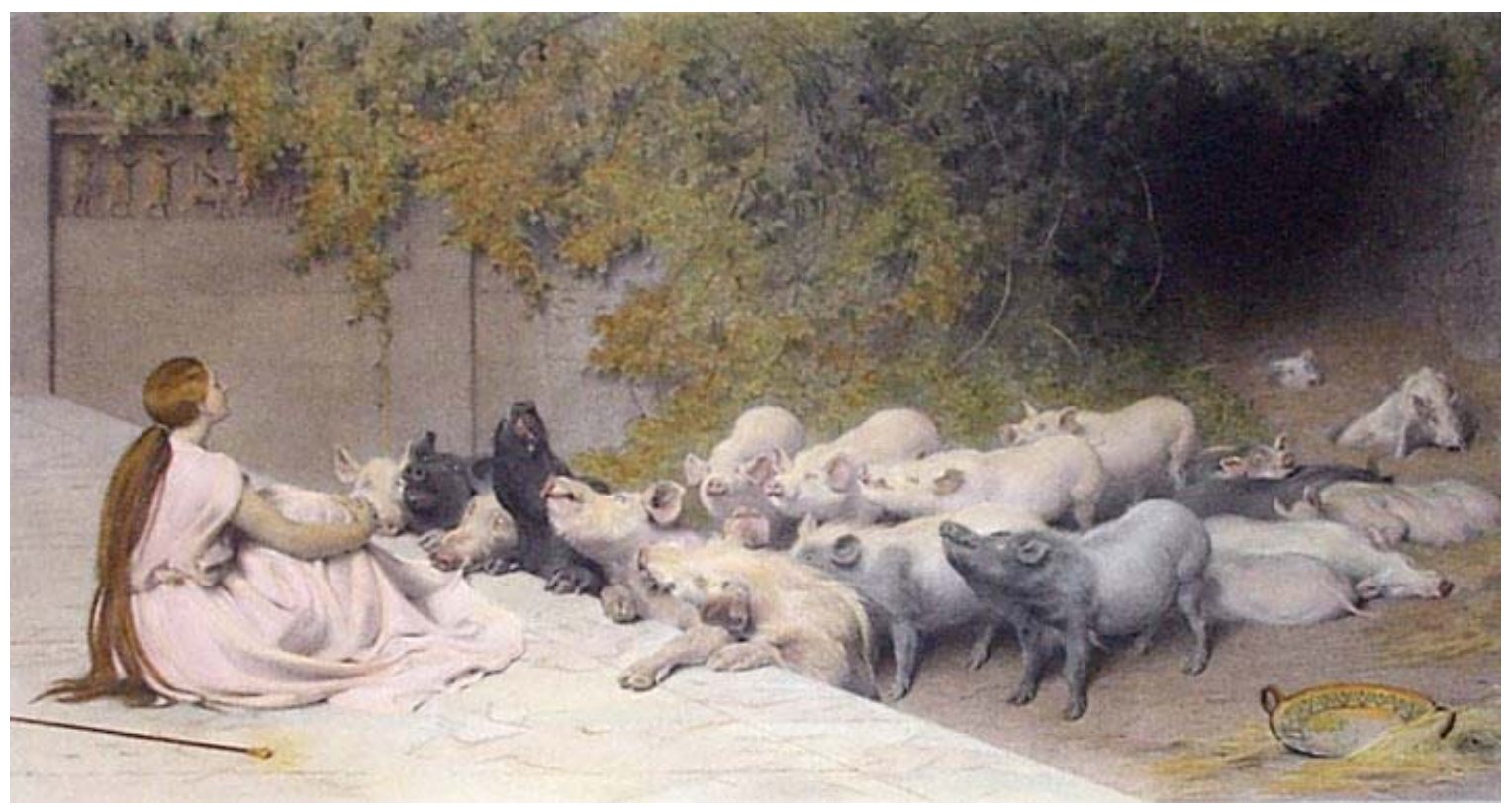

Fig. 1. Circe and her Swine. ${ }^{53}$

This research deals with knowledge as the material object for the thinking practice. It presents a truth that knowledge is a desire organized in relation to the action towards the object. The analysis of knowledge/power relation responds to the vocation of/for Science, "the dedication to the creation, preservation, and transmission of knowledge. ${ }^{54}$

Today the collaborative action of technology and human reframes the knowledge that has been thought as an idea, what knowledge is. It provides a new way of knowing beyond the logic of opposition; the mutual degradation between technology and human, thought and action, subject and object.

53 Circe and her Swine (1871) by Briton Riviere, Hand-printed etching, Manchester Art Gallery.

54 My research owes Joseph C. Pitt's research. Especially, this paper was inspired by the essay, "On the idea of a University" to Virginia Tech Science Studies Center Thursday Lunch Series, September 1995. In his article, Pitt examines how the idea of a university designates the knowledge/power relations. According to him, the crisis of idea of a university can be noticed by four problems; (1) the lack of institutional loyalty on the part of faculty and the culture of peripatetic administrators, (2) the general issue of institutional loyalty to the faculty, (3) the warping of the vision of the research university, and finally (4) the failure of the faculty to participate in public debate. These sources of crisis present that the danger is from the idea that underlines the knowledge in the regime of representation. In the idea, the university is degraded to the tool for the representation of knowledge. The instrumental perspective conceals the basic and essential inner vocation of university; the performing of knowledge as the presenting of ecological relations of thought and action. 
In order to understand the challenge of the collaborative action of technology and human, this study outlines 1) the problematic of the collaborative action of technology and human, and introduces 2) Aesthetic Technology as an frame work for the analysis of the knowledge/power relations, and reconsiders 3) the knowledge in three basic and essential characteristics: reflecting, performing, and invaginating.

\section{Reflecting Knowledge}

Technology is problematic. ${ }^{55}$ It participates in the human history; it changes human action and thought. In particular, computational technology is endowed with highly intelligent and perceptive qualities; has its own laws; and the system itself evolves. Technology performs the autonomous and emergent action beyond human control. With the ability of autonomy and emergence, technology becomes a performer (a collaborator) collaborating with humans.

The collaboration of technology and humans is problematic. It implies that the technology as performer (collaborator) transforms the human condition (the existence of human and its condition). The transformation, the expanded human condition by the technology can be called the collaborative condition of technology and human. It critiques the knowledge concealing the live relations between technology and human. The human-subject centered dichotomy assumes that human controls actions at his own will, while technology is a simple technological tool. ${ }^{56}$ It fosters the instrumental understanding on the relationship of technology and human. It defines the collaboration of technology and human as the represented relation that expresses the subjective experience through the representation of object. In the knowledge excluding technology as an equal partner, both technology and humans are subordinated into the

55 The term 'problematic' elaborated by Michel Foucault and Louis Althusser was to reveal the problem of knowledge system. Louis Althusser, For Marx (New York: Verso, 2005), Michel Foucault, Madness and Civilization (New York: Vintage, 1988), and Foucault, "Polemics, Politics, and Problematizations: An Interview,” The Foucault Reader (New York: Pantheon Books, 1984), 381-390.

${ }^{56}$ Hyunkyoung Cho, "The Performative Art; The Politics of The Doubleness," Leonardo, Vol. 42, No.3 (New York: The MIT Press, 2009), 282. 
instrumental, and the inter-action between them remains an impure one, a means to represent the knowledge itself (the knowledge system).

A solution for overcoming human-subject centered instrumental knowledge, the collaboration of technology and humans proposes a collaborative perspective; 'the collaborative being-with-the technology in the world.' It restores the significance of action as what happens in the realm of the presenting, and saves the real, lived, and free relation between technology and humans. It ultimately cultivates humanity that allows us to be critical, the examined and liberal life from the bondage of habit and custom. ${ }^{57}$

The collaborative action of technology and human rebuilds the history of action that has been degraded into the instrument to represent thinking. It embraces both the history of ideas (the analysis of systems of representations) and the history of mentalities (the analysis of attitudes and type of action). The eloquence of collaborative action of technology and human recalls that action is an apex of human activities, insofar as it testifies the multiplicity as the essence of life. In digital environments, the newness is that technology plays a role as a performer (a collaborator) like a human, and the process of technology-human interaction follows the logic of human communication; technology and humans directly acts and reacts as a human-human communication. The collaborative action of technology and human changes what the human is doing; how humans act. It means that the definition of human action should be reconsidered in the collaborative relationship with technology.

The collaborative action of technology and human proposes that technology and humans reciprocally share the action's process and its result. It denies the instrumental definition of inter-action; the human can use and control technology as a technological tool to represent the idea of human subject. This sharing weaves a hybrid network constituted by performers (collaborators) in an equitable manner. Thus collaborative action of technology and human leads us to a radical shift of knowledge/power on two

\footnotetext{
${ }^{57}$ Martha C. Nussbaum, Cultivating Humanity: A Classical Defense of Reform in Liberal Education (Cambridge: Harvard University Press, 2003), 1-50.
} 
points: from the human subject-centered dichotomy to the inter-subjective networking, from knowledge qua thinking to that qua acting. The shifts retain the spirit of humanity, its great intelligence, which does not define 'I' but performs 'We.'

\section{Performing Knowledge}

The collaborative action of technology and humans undermines the instrumental understanding of knowledge that has been thought as an idea, what knowledge is. It emphasizes the performing of knowledge; performed knowledge organizes the relation of action to object. Performing knowledge indicates that knowledge is a conjuncture at any given historical moment (current moment) to which analysis (including theory, analytic strategy, and tactics) must be applied; it can be only addressed in the analytic action as the process of analysis. ${ }^{58}$

Psychoanalytically speaking, performing knowledge denotes the state of overdetermination privileged by the condensation of a number of thoughts in a single image or the displacement of psychic energy from a particularly potent thought to apparently trivial images. ${ }^{59}$ The overdetermination implies that there is a relation between the 'transference' and 'suggestion' that the subject's demand makes; the socalled unconscious mechanisms of collaborative action of technology and humans, the marking of the demand of technology and humans qua counterpart. In other words,

\footnotetext{
58 The analysis is the understanding of the necessity of existing problems. It needs to theory, strategy, and tactics: "there can be no tactics that do not depend on a strategy-and no strategy that does not depend on theory." Althusser, "Marxism and Humanism," For Marx, 241.

${ }^{59}$ Here the word 'overdetermination' embraces both Materialism and Psychoanalysis's insight. In the book, 'The Interpretations of Dreams,' Sigmund Freud used the term overdetermination to explain the representation of the dream-thought. Jacques Lacan expands Freud's view into the structure of language. In Lacan's works, the concept of overdetermination is considered in the meaning of participation and retroaction, encounter (ex, encountering with the Real), chance, or fate (ex, fate of being towards the death). Jacques Lacan, The Seminar of Jacques Lacan, Book XI: The Four Fundamental Concepts of Psychoanalysis (New York: W.W. Norton \& Company Inc., 1998), The Seminar of Jacques Lacan, Book III: The Ethics of Psychoanalysis 1959-1960 (New York: W.W. Norton \& Company Inc., 1992), In Marxism, Althusser also used the same term to describe the effects of the contradictions in each practice. Althusser, "Contradiction and Overdetermination," For Marx, 89-130.
} 
performing knowledge is a doubling of effects, and it notes that the relation marking the subject's demand occurs between the transference of effects that corresponds within a subject to a particular demand and a suggestion as the effects of a position in relation to the 'other' that the performance sustains as subject. ${ }^{60}$ When performing involves overdetermination as doubleness, it substitutes knowledge for the relation to being where the action takes place; it perceives the resources producing knowledge/power. It means that performing knowledge is a return of the repressed knowledge in knowledge/power relations. Hence it can be only observed by symptoms. The symptom is the signifier of a signified that has been repressed from the subject's consciousness. ${ }^{61}$ What the linguistic conception teaches us is that the symptom proves its signifying function that differs from the natural index commonly designated by the term symptom in medicine. ${ }^{62}$

Performing knowledge as a symptom should be read within inter-subjective communication. Human language constitutes a kind of communication in which the sender receives his own message back from the receiver in an inverted form. ${ }^{63}$ Here the inverted form is the 'interpretation' of message. The interpretation of the repressed message in the process of return (repetition) of message (chain, communication) is the reading of symptoms. ${ }^{64}$ The symptomatic reading presents that knowledge is a desire performed in the action on an impossible and unapproachable object. ${ }^{65}$ It is no less than

${ }^{60}$ What is at stake in the process of transference and suggestion is that the performing knowledge can be only observed symptomatically. Lacan, "The direction of the treatment and principles of its power," Ecrits-A Selection (London: Routledge, 2001), 173-214.

${ }^{61}$ Lacan, "The Function and Field of Speech and Language in Psychoanalysis," Ecrits (New York: W.W. Norton \& Company, 2005), 232.

${ }^{62}$ Lacan, "The Freudian Thing," Ecrits, 348.

${ }^{63}$ Lacan, "Seminar on 'The Purloined Letter'," Ecrits, 42.

${ }^{64}$ In the necessity of symptomatic reading, we can understand what he meant when Lacan said that the consciousness is structured like a language, and it is the Other's discourse.

${ }^{65}$ Broadly speaking, the desire is the life itself, to live in love to life. It always involves a bit of madness; in some case, it is called as the genius or metal ill. But also there is always a bit of reason in the madness. Thus the poet and madness always meet on the extreme point or polarity of the signs called desire; "The madness brings similitude to the signs that speak it, whereas the 
the failure of action towards an object. In this sense, we can say that the essence of knowledge is in a truth-process performed in an action that must overcome itself again and again; the performing, the endless losing of self-evident holds the knowledge as a desire.

\section{Invaginating Knowledge}

Performing knowledge improved by the collaborative action of technology and humans cannot be considered in isolation. It results from social, cultural, economical, and/or political processes. It involves a certain number of factors to make it uncertain, that have made performing knowledge lose its familiarity. Interdisciplinarity testifies that performing of knowledge is not a making the world-view, but a reading in the theoretical framework, so-called concept in which it is used. Thus its intention seems to be that of instigation. Yet there is one element that is capable of discussing interdisciplinarity as the challenging of performing knowledge.

Aesthetic Technology is a problematization as one element-an analyzer for the analysis of the problematic of knowledge caused by the collaborative action of technology and humans in the collaborative condition. ${ }^{66}$ The problematization investigates diverse theoretico-practical solutions to produce a response of difficulties of the problem. It, however, is neither an arrangement of representations nor a construction of the knowledge of a collaborative action; it does not postulate the fixed concept. It is also far from a deconstruction in the sense that it differs from the production of another concept to manage the confusion between various disciplines or methods. It means that Aesthetic Technology is only centered on the absence of

poet loads all signs with a resemblance that ultimately erases them." Foucault, The Order of Things: An Archaeology of the Human Sciences (New York: Routledge, 2002), 55.

${ }^{66}$ The term 'Aesthetic Technology' was first presented in the paper, Hyunkyoung Cho, “Aesthetic Technology: Towards a New Aesthetic Value," Proceedings of The $7^{\text {th }}$ International Conference on Application and Principles of Information Science. Here the concept of Aesthetic Technology was defined as an attempt to approach the convergence of art, human, and technology. 
problems and concepts within the problem of knowledge provoked by the collaborative action of technology and human as much as its presence.

The analysis of Aesthetic Technology is invaginatory. It works in the terrain of the confrontation between the question and its answer. Instead of drawing a line of demarcation between question and answer, it invaginates the two into a solution. Here the invaginating knowledge is a 'seeking' to necessity of asking of an answering in a questioning (inquiry). ${ }^{67}$ It is an active 'investigating' for an entity both with regard to the fact that the problem of collaborative action is, and with regard to its reading as it is. It is guided beforehand by what is sought. Insofar as seeking something incorporates that which is asked about, knowledge is somehow an investigative questioning of something. In addition to what is asked about, there is a seeking of that which is interrogated.

To put it differently, the invaginating knowledge of Aesthetic Technology is a seeking questioning of a movement of critical analysis in which one tries to read how the different questions and answers to the problem have been constructed; but also how these different questions and answers result from its problem. It appears that any new solutions that might be added to the others would arise from the current problem of knowledge. In this sense, we could say that the invaginating of knowledge repeats one another. The essential point is that it is not a mere folding but an immanent and synthetic repetition. It produces the reiterating differences of self-reference in the selfreflexivity. ${ }^{68}$

${ }^{67}$ The word 'seeking' is used in Martin Heidegger's term. In the book, Being and Time, he defines being in time as Being, and considers the problematic of Being in a seeking for an asking of inquiry. For the examination, he assumes that "Every inquiry (Suchen) is a seeking (Suchen)." In English version of 'Sein und Zeit,' the Germen, Suchen is generally translated with the meaning of seeking or inquiry. The German word Erfragte is usually regarded as the meaning of asking. Martin Heidegger, Being and Time (London: Blackwell Publishing, 1962), 24. For the further study of the concept of seeking in Heidegger's insight, see Jacques Derrida's "The ends of Man," Margins of Philosophy (Chicago: University Of Chicago Press, 1985) 109-136.

${ }^{68}$ In this study, the concept of invagination refers to Derrida and Rosaline Krauss's notion. In the discourse of the narrative, Derrida describes it as "the folding of one story within another through the invention of a character who exactly repeats the opening of the first story, thereby setting it off on its narrative course once more." Krauss applies Derrida's notion into the modernist reflexivity of post-medium supported by technology. Derrida, "The Law of Genre," 
The invaginating knowledge intervenes in knowledge/power relations, systems of knowledge/power production. It questions the problem of knowledge itself, and poses its answer within its problem. The reconception of knowledge within knowledge reveals an essential lack of the knowledge based on the dichotomy, the binary frame. This lack can be explained with the understanding of supplementation. Philosophy as a knowledge defines the word 'supplement' as something that completes or makes an addition to complete. It means that the supplement supports both completeness and uncompleteness, and thus its understanding can be invested in the indeterminacy.

However, the supplementary structure has been considered in one perspective that defines the supplement as "an inessential extra, added to something complete it in itself." ${ }^{\prime \prime 9}$ The supplement serves to enhance the presence of something that is already complete and self-sufficient. This idea reinforces the dichotomy based on the logic of opposition; this perspective presupposes that the action is a supplement of thought; the object is a supplement of subject; technology is a supplement of humans. When knowledge is rooted from the supplementary structure supporting the logic of opposition, the so-called desire for the neutral such as performed knowledge is degraded as the immoral, ugly, and even dangerous. For example, in a dichotomy, the idea of a university is an attitude (experience) of human subject that represents knowledge of the object for the thinking practice. Judgment depends on the laws of morality and reason

Glyph 7 (Baltimore: Johns Hopkins University Press, 1980), 202-232. Rosaline Krauss, "Two Moments from the Post-Medium Condition," OCTOBER, Vol.116, No.1, Spring (New York: The MIT Press, 2006), 55-62.

${ }^{69}$ The logic of supplement was taken from Jean Jacques Rousseau. He used the term in order to explain the relationship between speech and writing. Derrida revisited Rousseau's logic of speech supplement. Rousseau notes that writing may become a 'dangerous supplement,' if it is used as a substitute for speech. Whereas, Derrida states that writing can be the supplement of speech. Even if writing is viewed as a supplement to speech, writing may still add meaning to speech, and it may still provide a kind of presence. Here, Derrida's emphasis is that there is an original lack of the supplementary structure rooted in Western thinking. In order to avoid the supplement between writing and speech, Derrida invokes the term invagination. Derrida, $O f$ Grammatology, and "Signature Event Context," Limited Inc (Evanston, IL: Northwestern University Press, 1988), 1-24. 
based on the logic of opposition of moral and immoral, good and evil; wherein what is universal is parallel to what is moral and good.

As an intervention on the knowledge/power system based on the logic of opposition, the invaginating knowledge of Aesthetic Technology admits the supplementary structure's incompleteness as the surplus derived from its essential lack. ${ }^{70}$ Insofar as the supplement is defined as an unessential extra addition to completeness itself, it is exactly what was supposed to be complete in itself. It grants that there is a hole originated from the incompleteness of the supplementary structure itself. Consequently, the invaginating knowledge explains that the supplement does not enhance the completeness's presence, but rather underscores its absence. When the absence, the hole should be filled by something, it is an essential lack. The lack evolves with a desire organized in the relation to action to object. The failure of action towards the impossible and untouchable object is what we call knowledge as reality constituted by the Real. ${ }^{71}$

70 The word 'lack' was used in Lacan's view. In Lacan's teaching, the matter of lack always involves with the desire. Even if the precise nature of what is lacking varies over the course of his work, the lack is essentially related to castration. It can be summarized as three characterizations; the lack of being, the lack of object, the lack of a signifier in the Other. See, Lacan's "On Freud's “Trieb" and the Psychoanalysis's Desire," Ecrits, 721-725. Derrida also used the term 'lack' in the discussion of structure. He insists that the supplement is to fill the original lack of Western thinking. See, Derrida, Of Grammatology, 298.

71 The words 'reality' and 'the Real' were used in Lacan's term. Lacanian notion of reality and the Real cannot be explained in the ideology that emphasizes the completeness of the supplementary structure. Lacan defines the reality as an image projected by the Real. This means that the reality is constitutive of the Real. Here, it should be mentioned that the relationship of reality and the Real does not to the completeness as the One, insofar as the reality is constituted by the Real. In the case, the Real is no less than the impossible, uncomplete. At this point, there is a parallel between Lacan and Marx's insight. Marx emphasizes that the real and lived relation (the human condition) is constituted by the actual life-process, not the consciousness. When Marx denies the reality constituted by its consciousness, Marx's 'the actual life-process' corresponds to Lacan's the Real. What both Marx and Lacan want to read is ultimately the problem of knowledge that reinforces the completeness what is supposed to be complete in itself. For the further study of Marx's insight, see Karl Marx and Friedrich Engles, The German Ideology (New York: International Publishers Co., 1970). 


\section{Recapitulation}

This research analyzes the knowledge as the material object for thinking as practice, through three keys: reflecting, performing, and invaginating. It examines that reflecting, performing and invaginating knowledge is improved by a collaborative action of technology and humans. And it proposes that knowledge is a desire based on the essential lack of the supplementary structure.

For the argument, this study outlines the problem of knowledge provoked by the collaborative action of technology and humans. To analyze the problem, it introduces Aesthetic Technology as an analyzer to address reflecting, performing, and invaginating knowledge. The analysis of Aesthetic Technology presents that performing knowledge is a return of the repressed; the overdetermination improved by the collaborative action of technology and humans. When performing knowledge can be only read by a symptom, it evolves with the invaginating as the dissolving of the binary frame into a solution.

As an attempt to re-conceive knowledge within knowledge (a reconception of knowledge in knowledge), invaginating knowledge articulates a truth that knowledge is a desire based on the essential lack of knowledge organized in relation to action upon the object. Insomuch as the action fails to capture the object, knowledge always remains as a desire for the impossible, untouchable, and prohibited object. This is why the collaborative action of technology and humans rejects the represented knowledge, the idea that expresses the knowledge in the regime of representation. 